\title{
A SYSTEM FOR THE MEDICAL EXAMINATION OF MASS CASUALTIES
}

\author{
Colonel W. M. ROSS, \\ M.D., F.R.C.S., F.F.R., D.M.R.T., late R.A.M.C. (T.A.) \\ $1(N)$ General Hospital (Territorial Army)
}

SINCE 1945 the words "mass casualties" have made us think of casualties caused by nuclear attack although in fact throughout the centuries there have been examples of mass casualty situations in both peace and war. A few examples which spring to mind are the earthquakes and tornadoes which are repeatedly encountered in certain parts of the world, the plague in the seventeenth century, and some battles in all major wars. During the Second World War one thinks of the heavy bombing attacks in London, the fire storm in Hamburg and other German cities, and the culminating attacks on Hiroshima and Nagasaki. The medical history of the First World War records many instances of very heavy casualties, perhaps the most notable being the Battle of the Somme in 1916. On the first July 1916, one of the early days of that battle, the Fourth British Army alone suffered 23,000 casualties and each main dressing station received about 1,500 wounded within 24 hours. This large number of wounded were dealt with under very difficult circumstances of accommodation by a small team led by only six medical officers.

There are many types of problem presented by mass casualties, and not all can be discussed in a short paper. The physical problems involved in receiving and moving the casualties have been investigated in military and civil defence exercises of the Millhand type, while minimal supportive medical measures of a type suitable for mass casualty situations have been described in the twenty-four supportive procedures for the R.A.M.C. Another aspect of the problem is that of examining the mass casualties and it is this aspect with which this paper deals. It is stressed that although in the paper most references are military in type, the suggested procedure is equally applicable to civilian situations. There is a feeling among doctors that they know all about examining patients, having done it repeatedly every day since they started as medical students, and that each patient must be considered as an individual rather than as one of a crowd, but throughout medical practice one accepts general rules and principles as a base on which individual - variations can be developed. Furthermore, a moment's thought will bring to mind the degree to which doctors vary in their method and efficiency of dealing with a problem, in their opinions especially on the details of a situation which is to a large extent hypothetical and in their preparedness to adhere to rule and instructions however thoroughly previous experience has justified such instructions.

It has been a cliche that medical lessons learned in the Boer War have had to be relearned successively in the World Wars and in Korea-as for example that sutures and casualty evacuation are incompatible.

\section{Footnote:}

Priorities mentioned on pages 4 and 5 and referred to at the end of this paper differ from those now incorporated in an amendment to the Field Surgical Pocket Book (1962) and discussed in another article in this number page 51 . 
Medical men are not immune to environmental stress and like others tend to be overwhelmed by a very large problem; under such circumstances they may act irrationally with the result that casualties suffer because of the lack of a clear cut plan. In the circumstances that we think would exist following a major disaster it is very difficult for a doctor not to be adversely influenced by the presence of so many people, some themselves injured, others bringing their injured friends and relatives. Many of those less seriously injured will aggravate a doctor's problem by crowding round him in an attempt to attract his attention, without waiting their turn. Among other factors the general level of noise under such conditions detracts from clear thinking and good work. The description of Dr. Sasaki working in a hospital at Hiroshima is to the point, "Here and there in his stockinged feet, staggered by numbers, bewildered by so much raw flesh, Dr. Sasaki lost all sense of profession and stopped working as a skilful surgeon and a sympathetic man; he became an automaton mechanically daubing, wiping, daubing, wiping ......".

It is, therefore, submitted that a systematised scheme of examination will help all doctors to reach and maintain the high standard normally expected of the most experienced, even under conditions of stress, and will ensure accurate diagnosis in the minimum time, following which the assessment of treatment priorities must be made so that the casualty can be moved to the appropriate place from the site at which he has been examined. The scheme of priorities which is given in the R.A.M.C. Training Pamphlet No. 2 is based on the assumption that all casualties will in a relatively short time be given the treatment appropriate to their injuries. Experience of sudden and mass casualty situations during and since the last war suggests that this assumption cannot always be accepted, as in the following instances:

In July, 1944 a flying bomb fell in Lewisham in London causing 300 casualties and 50 deaths. The roads quickly became blocked and ambulances held up in the traffic were quickly loaded with casualties at the perimeter with the resuit that it was one and a half hours before the first ambulances reached the centre of the incident where the more serious casualties were situated. The normal practice in Lewisham at that time did not include labelling of casualties and this may have contributed to the difficulties experienced in the sorting of casualties and the inevitable misdirection to hospitals and first aid posts. As a result even in a community well used to bombs and which had learnt to rescue its wounded efficiently the lack of labelling of casualties caused needless delay and difficulty in evacuating and therefore in treating them. The fire storm in Hamburg in July, 1944 also occurred in a community which had learnt over several years how to deal with the problems produced by frequent bombing, but the scale of this particular disaster was so unexpected and unprepared for that it completely overwhelmed the established services.

Since the second World War the Worcester (Massachusetts) Tornado in 1953, and the petrol explosion on the U.S.S. Bennington in 1954, are examples of events which almost overwhelmed arrangements which had appeared fully adequate to deal with every eventuality.

It is likely, therefore, that in some mass casualty situations limitations of supplies, personnel or treatment facilities will necessitate modification of the established priorities to maintain the axiom of the greatest good for the greatest number, and this may lead to some casualties being denied treatment. An alternative grouping of casualties was 
suggested by the United States Army and is as follows*:

* See footnote page 00 .

Priority 1(a).

Those requiring minimal treatment-

Small lacerations or contusions.

Simple fractures of small bones.

Second degree burns, less than 10 per cent (excluding face or hands).

Acute whole body radiation $<150$ rads.

Priority $1(b)$.

As 1(a) but who may require some degree of untrained help.

e.g. Disabling minor fractures.

Burns of face or hands making self help difficult.

Minor neuropsychiatric disorders.

Early symptoms of acute radiation damage.

\section{Priority 2.}

Those requiring immediate care-

Haemorrhage from accessible site.

Rapidly correctible mechanical respiratory defects.

Severe crush injuries of extremities.

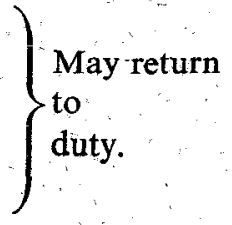

Incomplete amputations.

Severe laceration with fracture of long bones.

Severe burns of face and URT needing tracheostomy.

Priority 3.

Those whose surgical treatment may be delayed-

Simple fracture of major bones.

Moderate lacerations without severe bleeding.

Second degree burns of 10-20 per cent body surface.

Third degree burns of 10-30 per cent body surface.

Non critical CNS injuries.

Priority 4.

Those whose therapy will be expectànt but not masterful neglect-

Critical injuries of CNS or respiratory system.

Penetrating or perforating abdominal injuries.

Multiple severe injuries.

Severe burns of large areas ( $>40$ per cent).

Established lethal or supralethal doses of radiation.

$\left\{\begin{array}{l}\text { A short } \\ \text { procedure }\end{array}\right.$

$\int \begin{aligned} & \text { may } \\ & \text { save } \\ & \text { life. }\end{aligned}$

It is immediately apparent that the most serious cases, those whom in civilian life and normal casualty work are given first priority, may under mass casualty situations rate a low priority because of the surgical man-hours and the facilities which each one requires for successful treatment and which would detract from the treatment of other casualties.

\section{Examination Procedure}

A standard examination procedure is indicated so that the medical officer may accurately allot the casualty to the appropriate priority group. The following procedure 
is based on one demonstrated at the British Military Hospital, Hannover during the Director of Medical Services' Annual Study Period in 1962.

Note the patient's position and his state of consciousness by his response to a simple enquiry: his mental state is noted with reference to alertness or anxiety, drownsiness or weakness.

Note the skin temperature, circulation and the presence or absence of sweating. Look for pallor, flushing or cyanosis.

Note the character, rate, regularity and depth of respiration. If there is any respiratory distress, look immediately for mediastinal shift and gross changes in air entry. A case of this type may need priority treatment.

Note the rate, regularity and volume of the pulse: estimate the systolic blood pressure.

Ascertain the cause of injury, the time it occurred and the position of the patient at the time. Also ask about bleeding since the injury

General and whether urine has been passed.

\section{Regional examination}

The full physical examination works methodically downwards from the head. Observe and palpate the scalp for bruising, tenderness, deformity or presence of a wound. Palpate the neck and cervical spine. Examine for cervical rigidity. Note the ears for bleeding, the eyes for pupil abnormality and test the eye movements. Note the mouth and tongue for injury and the presence or absence of sputum, blood and debris.

Examine for bleeding, injury and muscle tone: test the joint movements.

Examine the chest for crushing or penetrating wounds, palpate the Colour and feel of skin of face.

Respiration

Pulse

History thoracic spine and compress the chest. Then auscultate.

Examine for signs of injury. Palpate all over including the flanks and lumbar spine. Compress the pelvis.

Head and

Neck

Examine all over and test movements of joints: elicit plantar reflexes and muscle tone.

Inspect the posterior of the patient for injuries and bleeding.

Upper limb

Chest

Abdomen and Pelvis

Lower limbs

Back

It was recognised that such an examination would be time-consuming and fatiguing and that, unless aided by good team work and organisation, a doctor would be able systematically to examine only an unacceptably small number of injured in a given time. His useful contribution to the process of sorting the wounded will be much diminished unless those injured who do not appear to require a searching medical examination are identified and dealt with by trained lay personnel. The latter will also undertake suitable medical and administrative tasks, notably that of simple documentation.

Within the scheme of examination suggested above an experienced doctor will quickly begin to shorten the time required in several ways, such as by doing two things at once. For example when asking the few questions involved he will observe the patient 
and may estimate the state of the pulse. However, we have postulated that the examination is done by a very experienced doctor such as an anaesthetist or surgeon who is accustomed to dealing with seriously injured people, rapidly assessing their condition, and who is still reasonably fresh and untired. Furthermore the conditions were assumed to be satisfactory both as regards space and lighting and the preparation of the patient for the examination; also no mention has yet been made of the final method of recording the doctor's findings. It is likely that under the conditions of mass casualties the circumstances will be less favourable in several aspects and it is our aim in suggesting the system to try to overcome these less favourable circumstances.

To enable the doctor to give of his best two measures are suggested: (1) to have the patient examined immediately prior to the doctor by experienced lay people who are familiar with the system of recording, and (2) by establishing a system of policing and control which will ensure that urgent casualties rapidly reach a doctor and that all other casualties who require his attention reach him in an orderly manner. In the small team immediately ahead of the doctor there would be one clerk and two medical assistants. It would be the duty of the clerk to initiate the F.Med.26 and to record upon it such identification details as name, number and unit and time and situation where the casualty was wounded. The first medical assistant would loosen any dressings and clothing without, however, removing them unless they were grossly contaminated as there is likely to be a shortage both of fresh dressings and clothing and of facilities for disposing of any clothing which is removed. He should quickly assess the patient's general condition, look for any active bleeding, and record the pulse. The second medical assistant would then record the seven B's: brain state, breathing, blood pressure, bowels, bones, back and bleeding.

In recording the patient's state under these headings this medical assistant sets in motion the system to be followed throughout the patient's course, namely that only abnormal findings are recorded, it being understood that no entry means a normal finding. It is appreciated that this ideal demands a high degree of reliance on every member of the team, but it is felt essential to avoid unnecessary re-examination and to limit the amount of writing which is done. As a result when the medical officer sees the casualty his work is restricted to checking any of the medical assistant's findings, which he considers necessary, completing the examination on the scheme suggested and assessing priority and disposal. He dictates the few words necessary to his clerk who enters them on the F.Med.26 which, of course, continues with the patient.

The policing and control of the area where the medical examinations are being carried out is a complicated scheme in which it will always be found impossible to have too many people. Ideally there should be one entrance only to the site and at this entrance there should be a policeman and an experienced nursing orderly or trained sister whose duty it is to divide the casualties rapidly into three categories. (1) The very small number who require emergency treatment, usually for haemorrhage or asphyxia to avoid death within a few moments, (2) the large group, probably more than half og the total, of walking or lightly wounded who do not require to be seen by a medical officer, and (3) the group of casualties who do require examination by the doctor and who if possible are divided into conscious and unconscious streams.

The group requiring emergency treatment, such as the arrest of major bleeding from an incomplete amputation, must not be allowed to interfere with the routine of the sorting 
medical officer, but instead diverted to one of his colleagues whose duty it is to deal with such emergencies. The lightly wounded may be seen by a nursing officer or nursing orderly, or a doctor if one is available, given minimal treatment and allotted to priority one. The more seriously injured are taken to the medical officer, preceded by the examination team already described, and it if is convenient to have two doctors examining simultaneously, divided into the conscious and unconscious streams. These teams allocate these casualties to priorities two, three or four as appropriate. A major shortage at all times is likely to be people to carry the casualties, with or without stretchers. It will, in fact, be impossible to have too many such people and all available personnel will be pressed into service. These include anyone from the detachment or parent unit not otherwise engaged, relatives or comrades of the injured who are not themselves casualties and probably some at least of the lightly injured. A suggested scheme for the layout of such an organisation is shown assuming that four medical officers are available. If fewer doctors are present the care first of the lightly wounded and then of the emergency section could be undertaken by non-medical personnel.

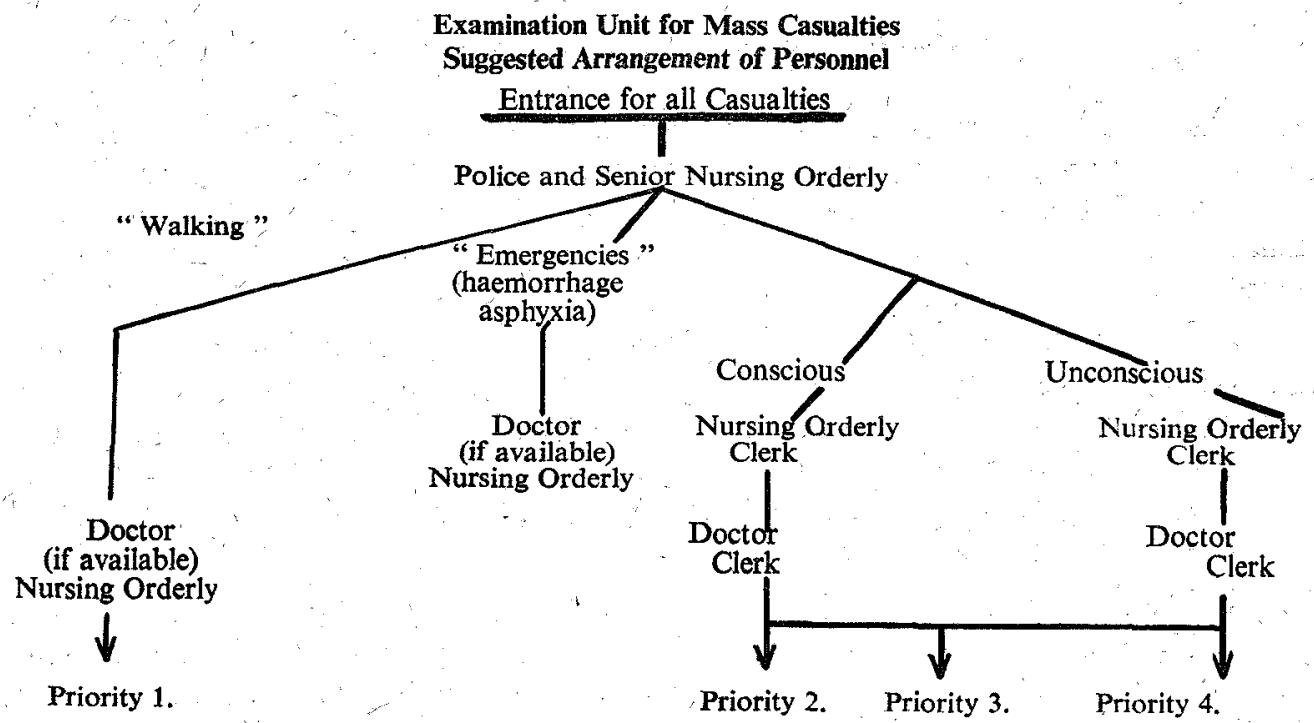

Fatigue from repetitious work and from long hours is certain to be a cause of increasing inefficiency, and both doctors and laymen should be compelled to rest at intervals if it is possible in the circumstances to provide reliefs, or to exchange duties between themselves. It is felt that under reasonably satisfactory conditions two doctors undertaking the main examinations could, without an unacceptable loss of professional standards examine some 1,000 patients in 16 hours.

Although no attempt is made here to consider many of the problems which will inevitably arise in a situation such as we are considering, for example the space required to house 1,000 stretchers or the problems of supplying minimal requirements of food, drink, heat and fresh materials to the personnel one administrative point should be stressed, that is the necessity for recording in a book of the admissions and discharge 